\title{
Surface Characterisation of Spin Coated Quaternary Chalcogenide CZT(S, O) Thin Film for Optoelectronic Applications
}

\author{
Rafiu Adewale Busari ${ }^{1}$, Bidini Alade Taleatu ${ }^{1, ~}$, Saheed Adekunle Adewinbi ${ }^{1,2}$, \\ Olusegun Emanuel Adewumi ${ }^{1}$, Adeniyi Yisau Fasasi ${ }^{3}$ \\ ${ }^{1}$ Department of Physics and Engineering Physics, Obafemi Awolowo University, Ile-Ife, Nigeria \\ ${ }^{2}$ Department of Physics, Osun State University, Osogbo, Nigeria \\ ${ }^{3}$ Centre for Energy Research and Development, Obafemi Awolowo University, Ile-Ife, Nigeria
}

\section{Email address:}

bdntaleatu@oauife.edu.ng (B. A. Taleatu)

${ }^{*}$ Corresponding author

\section{To cite this article:}

Rafiu Adewale Busari, Bidini Alade Taleatu, Saheed Adekunle Adewinbi, Olusegun Emanuel Adewumi, Adeniyi Yisau Fasasi. Surface Characterisation of Spin Coated Quaternary Chalcogenide CZT(S, O) Thin Film for Optoelectronic Applications. Journal of Photonic Materials and Technology. Vol. 5, No. 2, 2019, pp. 38-45. doi: 10.11648/j.jmpt.20190502.13

Received: November 8, 2019; Accepted: December 4, 2019; Published: January 7, 2020

\begin{abstract}
Thin films of copper zinc tin sulphide (CZTS) have been deposited on glass substrate at various solution concentration and angular speed using sol-gel spin coating technique. Surface morphology showed that the deposited layers are continuous and pinhole free. The film's particles are evenly distributed and adhered firmly to the substrates. X-ray diffraction studies revealed that the films are polycrystalline with tetragonal kesterite structure. Interplanar spacing and average crystallite size were estimated as $3.732 \AA$ and $56.53 \mathrm{~nm}$. Film's thickness and stoichiometry were determined from Rutherford Backscattering Spectroscopy (RBS) as $127 \mathrm{~nm}$ and $\mathrm{Cu}_{1.5} \mathrm{Zn}_{1.0} \mathrm{Sn}_{1.1} \mathrm{~S}_{4.4} \mathrm{O}_{3.3 .}$. Optical studies showed that the deposited films exhibit direct band transition. The values of the energy gap were found between 1.30 and $1.60 \mathrm{eV}$. The result of the study suggested that the deposited CZTS thin films can perform as a good absorber material in nanostructured optoelectronic devices.
\end{abstract}

Keywords: Polycrystalline, Sol-gel Spin Coating, Surface Morphology, Crystal Diffraction, Optoelectronic Devices

\section{Introduction}

One of the very viable clean energy supply that can meet the demand of human population and industries is solar energy, but its production is costly because of the technology involved. Many thin film materials have been investigated for the development of next generation efficient and costeffective solar devices. Among them are Copper Indium Gallium Selenide (CIGS), Cadmium Telluride (CdTe), perovskites and so on. Their syntheses have reached commercialisation stage [1-3]. However, scarcity and toxicity of some of the elements, for example, Indium, Cadmium and Selenium, increasingly impede the development of solar devices based on these materials. To develop photovoltaic materials that are cost-effective and eco-friendly, elements that are non-toxic and readily available are desired. In this context, Copper, Zinc and Tin have been found as respective replacements for Indium, Cadmium and Tellurium in the making of Copper Zinc Tin Sulphide thin film (CZTS). CZTS thin films have been reported to be efficient and sustainable solar cell materials. They possess good optoelectronic properties, near optimal direct band gap energy ranging from 1.4 to $1.6 \mathrm{eV}$ and high optical coefficient $\left(\geq 10^{4} \mathrm{~cm}^{-1}\right)[4,5]$. Several deposition techniques have been used to synthesise CZTS thin film. These include pulsed laser deposition, co-sputtering, thermal evaporation, electrodeposition, sol-gel spin coating, spray pyrolysis, and so on [6-8]. Among them, sol-gel method is one of the most widely used because of its simplicity, high material utilization, and facile control of the precursor ratio [7].

In this study, we report the growth ofCZTS thin film from 
precursor containing inorganic reagents and EDTA (complexing agent) using sol-gel spin coating technique. The substrate is microscopic glass slide. The properties of the samples were examined by various surface characterization studies. From the results of the characterization, the growth process could easily be scaled up for industrial production.

\section{Experimental}

All chemical reagents in the experiment are analytical grade (Sigmal - Aldrich). They were used as received. The microscopic glass slide substrates were cleaned by scrubbing thoroughly with cotton bud and soap solution, rinsed with running tap water and then ultrasonicated with distilled water, acetone and methanol at $40^{\circ} \mathrm{C}$ for ten minutes each. They were dried briefly in open furnace. The growth device is Osilla spin coater (E440) from Osilla Limited, Sheffield, UK.

\subsection{Samples Preparation}

Three different samples were prepared. They are named A1, A2 and A3, respectively. Each of the samples was obtained from separate sol-gel precursor. Sample A1 was deposited from precursor comprises $20 \mathrm{~mL}$ of $0.25 \mathrm{M}$ of $\mathrm{CuSO}_{4} .5 \mathrm{H}_{2} \mathrm{O}, 10 \mathrm{~mL}$ of $0.15 \mathrm{M}$ of $\mathrm{Zn}\left(\mathrm{NO}_{3}\right)_{2}, 10 \mathrm{~mL}$ of 0.15 $\mathrm{M}$ of $\mathrm{SnSO}_{4}, 20 \mathrm{~mL}$ of $0.3 \mathrm{M}$ of $\mathrm{Na}_{2} \mathrm{~S}_{2} \mathrm{O}_{3} .5 \mathrm{H}_{2} \mathrm{O}$ and $10 \mathrm{~mL}$ of $0.04 \mathrm{M}$ of EDTA. The dissolving agent was methanol. The solution was stirred at $50^{\circ} \mathrm{C}$ for 10 minutes after which a brownish gel was formed. The gel was allowed to cool. It was then spin coated on the clean glass substrate at an angular speed of $2500 \mathrm{rpm}$ for 30 seconds. Coating was repeated seven times to obtain desirable thickness and uniformity of the film. For samples A2 and A3, the precursors were prepared in the same way. The concentration of $\mathrm{Na}_{2} \mathrm{~S}_{2} \mathrm{O}_{3} .5 \mathrm{H}_{2} \mathrm{O}$ in the precursor of $\mathrm{A} 3$ is $0.075 \mathrm{M}$ and it took longer time for it to become gelatinous. The spin speeds for the deposition were the same. Details of the coating conditions are presented in Table 1. After obtaining the samples, they were dried in open furnace at about $120^{\circ} \mathrm{C}$ for 5 minutes. Figure 1 gives a schematic representation of the preparation processes.

\subsection{Characterisation Techniques}

Crystal structure of the films was studied by X-ray diffraction (XRD) technique using an XPERTPRO Diffractometer (PANalytical BV, The Netherlands) with $\mathrm{CuK} \alpha$ radiation source ( $\lambda=1.5406 \AA$ ). Surface morphology of the films was observed by field emission scanning electron microscopy (FE-SEM) and optical properties were examined by a SHIMADZU UV-1800 double beam spectrophotometer in the wavelength range $200-$ $800 \mathrm{~nm}$, respectively. Compositional studies, films' thickness and stoichiometry were obtained using Rutherford backscattered spectroscopy (RBS) technique.

Table 1. Details of the Precursor and Growth Condition for Spin Coated CZT (S, O) Samples.

\begin{tabular}{llll}
\hline Samples & Spin speed (rpm) & $\mathbf{C u S O}_{\mathbf{4}} \mathbf{5} \mathbf{H}_{\mathbf{2}} \mathbf{O}$ & $\mathbf{Z n}_{(\mathbf{N O})_{2}}$ \\
\hline A1 & 2500 & $0.25 \mathrm{M}, 20 \mathrm{~mL}$ & $0.15 \mathrm{M}, 10 \mathrm{~mL}$ \\
A2 & 3000 & $0.25 \mathrm{M}, 20 \mathrm{~mL}$ & $0.15 \mathrm{M}, 10 \mathrm{~mL}$ \\
A3 & 3000 & $0.25 \mathrm{M}, 20 \mathrm{~mL}$ & $0.15 \mathrm{M}, 10 \mathrm{~mL}, 10 \mathrm{~mL}$ \\
\hline
\end{tabular}

Table 1. Continued.

\begin{tabular}{lllll}
\hline Samples & $\mathbf{N a}_{2} \mathbf{S}_{\mathbf{2}} \mathbf{O}_{\mathbf{3}} \mathbf{. 5} \mathbf{H}_{\mathbf{2}} \mathbf{O}$ & EDTA & Spin time (sec) \\
\hline A1 & $0.3 \mathrm{M}, 20 \mathrm{~mL}$ & $0.04 \mathrm{M}, 10 \mathrm{~mL}$ & 30 & 7 \\
A2 & $0.3 \mathrm{M}, 20 \mathrm{~mL}$ & $0.04 \mathrm{M}, 10 \mathrm{~mL}$ & 30 & 7 \\
A3 & $0.075 \mathrm{M}, 20 \mathrm{~mL}$ & $0.04 \mathrm{M}, 10 \mathrm{~mL}$ & 30 & 7 \\
\hline
\end{tabular}

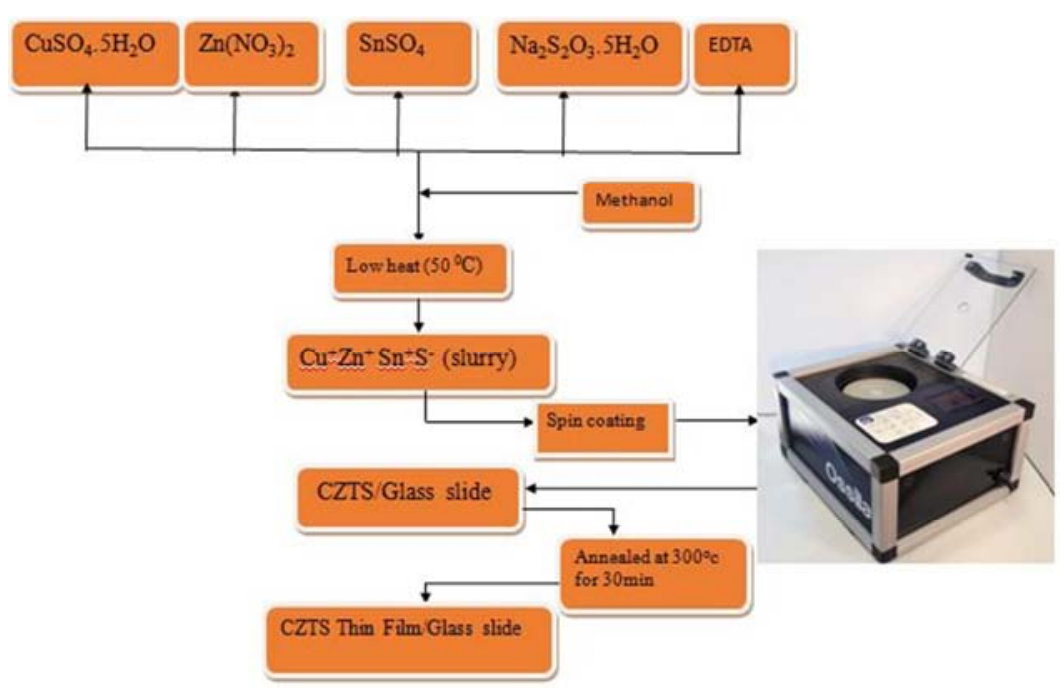

Figure 1. Schematic diagram of the experimental procedure. 


\section{Results and Discussion}

\subsection{Crystal Structure}

The diffraction patterns of the samples are presented in Figure 2. From the figure, the presence of multiple peaks in all the patterns confirmed the polycrystalline nature of the deposited films [9]. In samples A1 and A2, the diffraction peaks observed at $2 \theta=28.27^{\circ}, 32.26^{\circ}, 37.49^{\circ}$ and $47.35^{\circ}$ correspond to reflections from planes (112), (200),(211) and (220) of $\mathrm{Cu}_{2} \mathrm{ZnSnS}_{4}$ (CZTS). Also in sample A3, the peaks at $2 \theta=18.13^{\circ}, 33.34^{\circ}, 37.49^{\circ}$ and $47.35^{\circ}$ correspond to reflection from planes (101), (202), (211) and (220). These reflections are identifiable characteristics of tetragonal $\mathrm{Cu}_{2} \mathrm{ZnSnS}_{4}$ havingkesterite body centered structure (JCPDS card no. 26-0575). Little peak broadening noticed in samples A1 and A2 at plane (200) can be attributed to unintended ions impurity from higher concentration of $\mathrm{Na}_{2} \mathrm{~S}_{2} \mathrm{O}_{3} .5 \mathrm{H}_{2} \mathrm{O}$. Additional peak found in sample A3 at $2 \theta=26.39^{\circ}$ can be assigned to (100) crystal plane of $\mathrm{Cu}_{3} \mathrm{SnS}_{3}$ phase according to JCPDS card no. 29-0584. This observation can be supported with the findings of Subramaniam et al. (2014) which indicated that a quaternary compound of $\mathrm{Cu}_{2} \mathrm{ZnSnS}_{4}$ often contains other binary or ternary phase [10]. Therefore, a good control of synthesis to achieve the required phase of the material is essential. Other peaks in the patterns can be traced to the substrate and likely impurities from the precursor. The generally low peak intensities observed in samples A1 and A2 can be attributed to the presence of oxygen in the preparation of precursors (as confirmed from the RBS result). It has been reported that peak intensity of thin film can decrease with increase in oxygen component [11]. The dominant peak observed at angle $2 \theta=28.27^{\circ}$ in samples A1 and
A2indicatesthat their preferred growth orientation is along (112) plane, while the peak at $18.13^{\circ}$ in sample A3 shows its preferred orientation along (101) plane. Other parameters (see Table 2) for further appraisal of the crystal structure of the films are estimated according to some expressions below.

Lattice parameters of the deposited film were estimated using the relation for tetragonal crystal structure given as

$$
\frac{1}{d^{2}}=\frac{h^{2}+k^{2}}{a^{2}}+\frac{l^{2}}{c^{2}}
$$

Where $d$ is the interplanar spacing; $h, k$ and $l$ are Miller indices; a and c are the lattice constants.

The crystallite size D of the film was determined from the XRD peaks using the Debye-Scherrer's equation [12]

$$
D=\frac{0.94 \lambda}{\beta \cos \theta}
$$

Where $\beta$ is full width at half maximum (FWHM) of the peak in radians, $\theta$ is the peak angle and $\lambda$ is the $\mathrm{x}$-ray wavelength.

Dislocation density, $\delta$ is determined from the Williamson and Smallman's relation [12].

$$
\delta=\frac{1}{D^{2}}
$$

The induced strain in the samples was calculated using:

$$
\epsilon=\frac{\beta \cos \theta}{4}
$$

The number of crystallites per unit area was also determined using the equation:

\begin{tabular}{|c|c|c|c|c|c|c|c|c|c|c|}
\hline $\mathrm{S} / \mathrm{n}$ & Samples & $2 \theta\left({ }^{\circ}\right)$ & (hkl) & FWHM ( $\beta$ ) & Lattice Contants $(\AA ̊)$ a b & d $(\AA)$ & D (nm) & $\delta(\mathrm{nm})^{-2}$ & $\varepsilon$ & $\mathbf{N}$ \\
\hline 1 & A1 & 28.27 & $(112)$ & 0.197 & 10.690 & 3.154 & 75.82 & 1.74 & 0.05 & 289.06 \\
\hline 2 & $\mathrm{~A} 2$ & 28.27 & (112) & 0.253 & 10.690 & 3.154 & 59.11 & 2.86 & 0.06 & 615.01 \\
\hline 3 & A3 & 18.13 & $(101)$ & 0.423 & 3.431 & 4.888 & 34.67 & 8.32 & 0.10 & 3071.75 \\
\hline
\end{tabular}

$$
N=\frac{t}{\left(D^{3}\right)}
$$

Table 2. Some calculated parameters for evaluation of the crystallinity of the samples.

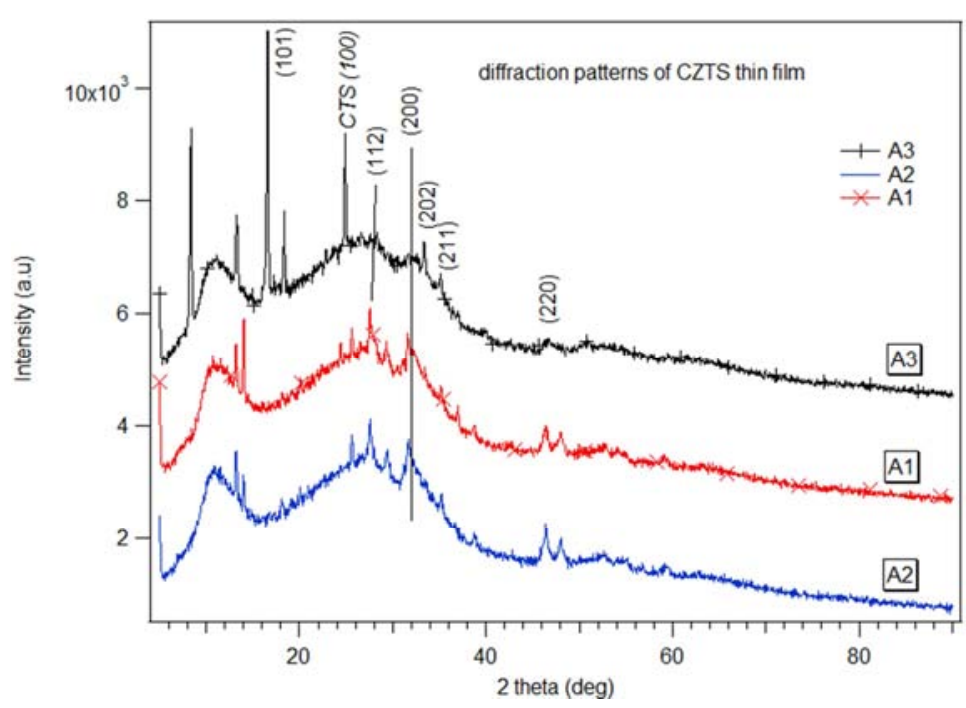

Figure 2. XRD patterns of deposited CZTS thin films. 


\subsection{Surface Morphology}

The SEM images are presented in Figure 3 (a-c). The images correspond to samples A1, A2 and A3 respectively. From the micrographs, it is observed that films are well adhered to the substrate with presence of numerous nanoclusters across the substrate's surface. The nanoclusters get agglomerated to each other to form polycrystals. Samples obtained at higher spin speed show bigger grains that are also evenly distributed (A2 and A3). They appear sharper with more distinct grains. From the Figures, very little voids and pores are noticed in all the films; and this suggests that the films can minimize migration of impurities. Such little number of voids in thin film absorber solar devices does not significantly mitigate photon conversion efficiencies [13]. Also, the observed nanopores are useful for better performance of the films in the fabrication of dye sensitised solar cells and gas sensor devices [14]. Therefore, agood control of atomic content is important to obtain a large grain size, less number of voids and considerable porous layer.
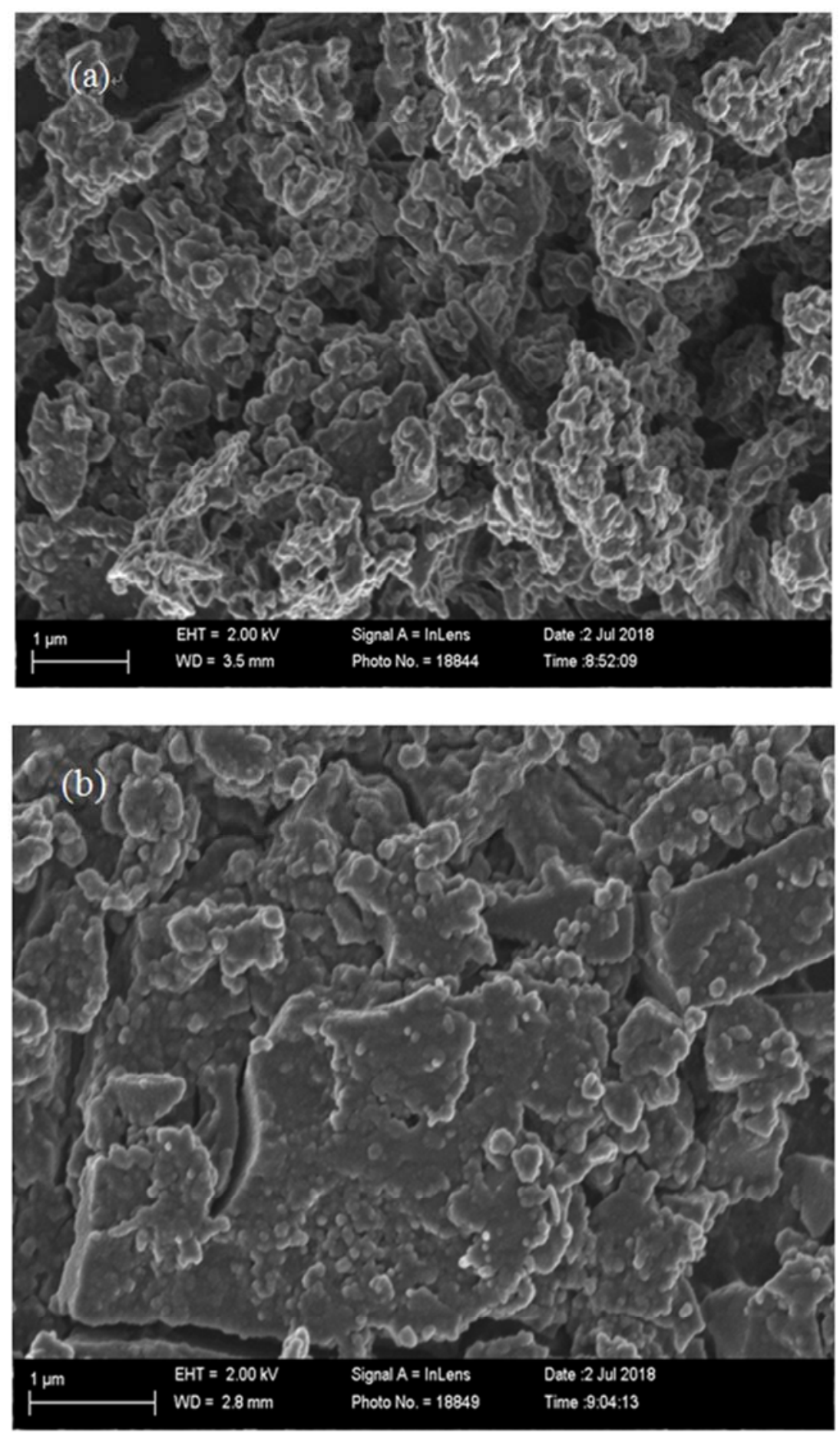


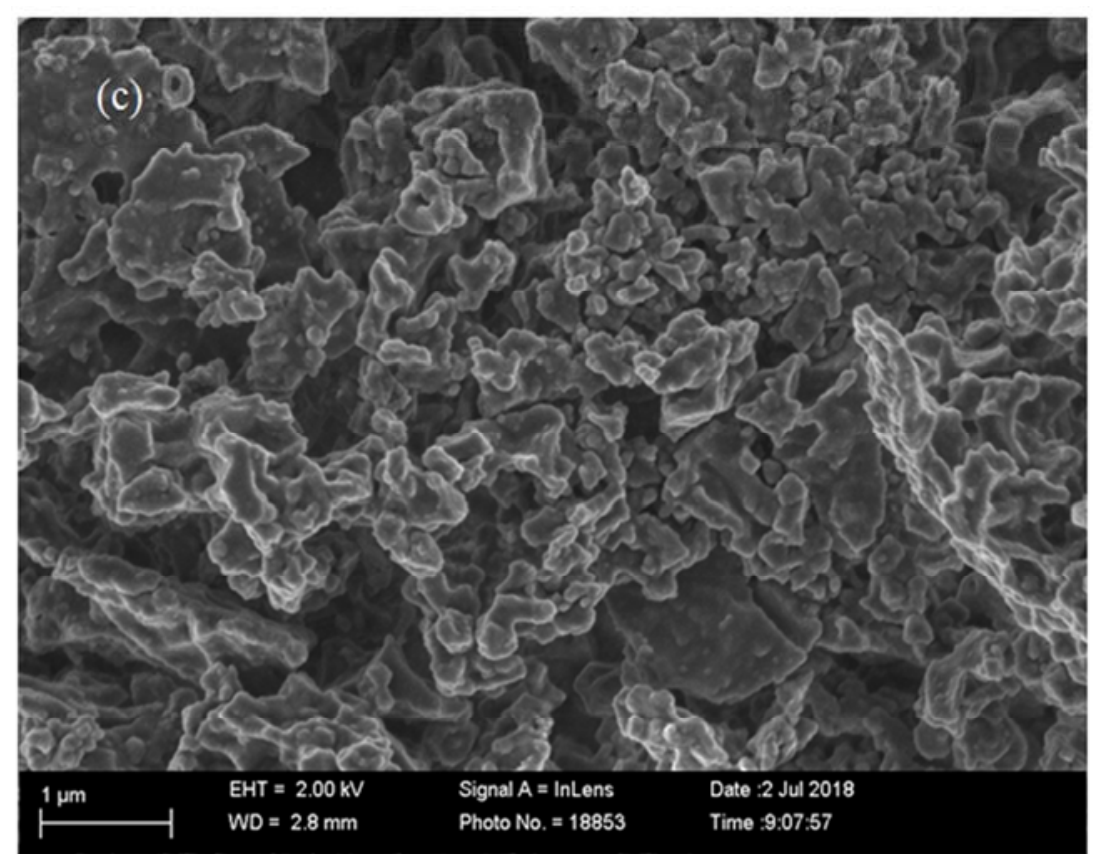

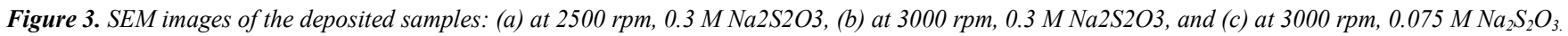

\subsection{Films Composition, Thickness and Stoichiometry}

Energy dispersive X-ray spectroscopy (EDX) spectra of CZTS thin film is shown in Figure 4. From the spectrum, signals of the films composition $(\mathrm{Cu}, \mathrm{Zn}, \mathrm{Sn}$ and $\mathrm{S})$ are identified. Other observed signals in the spectrum may probably originate from the glass substrate. Furthermore, investigation of constituent elements, thickness and stoichiometry of the film were carried out by RBS studies. The results confirmed the presence of copper, zinc, tin, sulphur and oxygen in the samples (see Figure 5). Estimated values of the stoichiometry are presented in Table 3. From the Table, the ratio of $\mathrm{Cu}, \mathrm{Zn}, \mathrm{Sn}, \mathrm{S}$ and $\mathrm{O}$ can be written as $\mathrm{Cu}_{1.5} \mathrm{Zn}_{1.0} \mathrm{Sn}_{1.1} \mathrm{~S}_{4.4} \mathrm{O}_{3.3}$, indicating that the deposited film is oxy-sulphide. The estimated thickness of the samples A1, A2 and $\mathrm{A} 3$ are 126, 127 and $128 \mathrm{~nm}$ respectively.

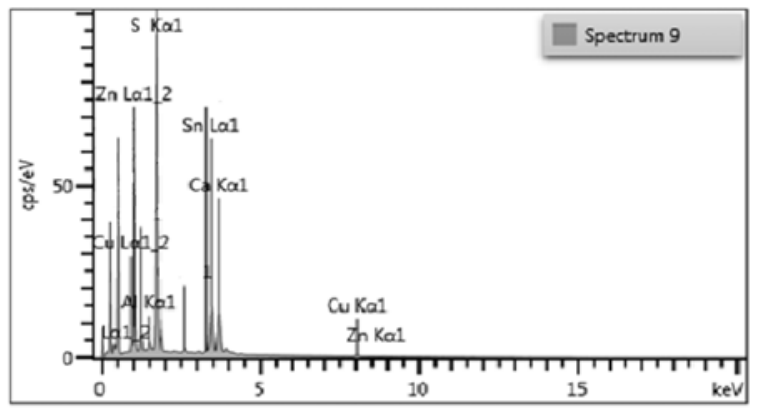

Figure 4. EDX spectrum of the deposited CZTS film.

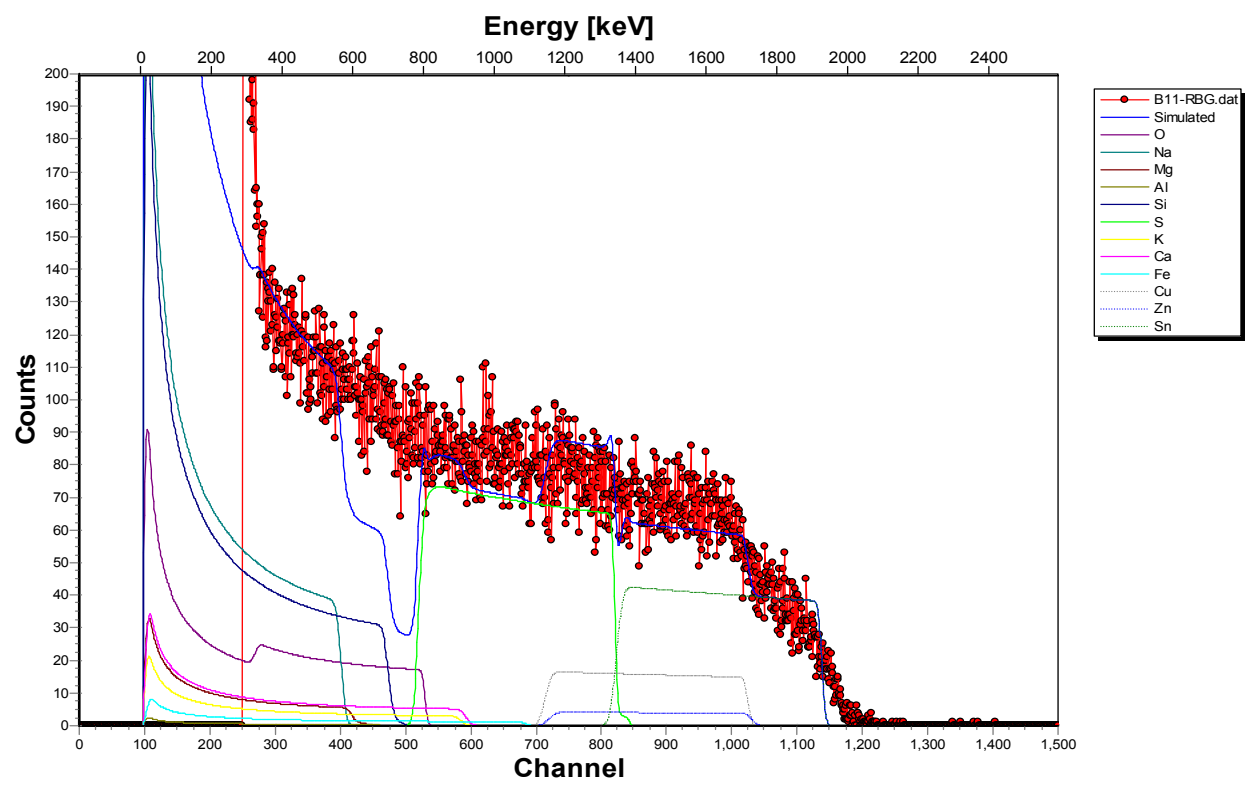

Figure 5. RBS spectrum of the sample. 
Table 3. Elemental composition of the spin coated CZT (S, O) thin film.

\begin{tabular}{lll}
\hline Element & Composition (\%) & Ratio \\
\hline $\mathrm{Cu}$ & 13.10 & 1.5 \\
$\mathrm{Zn}$ & 8.74 & 1.0 \\
$\mathrm{Sn}$ & 9.73 & 1.1 \\
$\mathrm{~S}$ & 38.51 & 4.4 \\
$\mathrm{O}$ & 28.92 & 3.3 \\
\hline
\end{tabular}

\subsection{Optical Characterisation}

\subsubsection{Film's Absorbance and Transmittance}

The optical investigation depends on the measurement of absorbance, $A(\lambda)$, and transmittance, $T(\lambda)$ in the spectra range between 200 and $800 \mathrm{~nm}$. These data are utilised to obtain absorption coefficient $(\alpha)$, optical band gap energy $\left(E_{\mathrm{g}}\right)$, and skin-depth $(\delta)[13,14]$. Absorbance spectra of the samples are presented in Figure 6. It is observed from the spectra that sample A3 deposited at $3000 \mathrm{rpm}$ and $0.075 \mathrm{M}$ of $\mathrm{Na}_{2} \mathrm{~S}_{2} \mathrm{O}_{3} .5 \mathrm{H}_{2} \mathrm{O}$ showed highest absorption power in UV-Vis region. This can be attributed to longer time taken by the precursor of sample A3 to become gelatinous during preparation. The precursor also appears considerably thicker and stickier than those of samples A1 and A2. However, it can also be seen from the spectra that sample A2 has higher absorption than A1. This variation can be traced to lower coating speed (2500 rpm) of the sample A1.

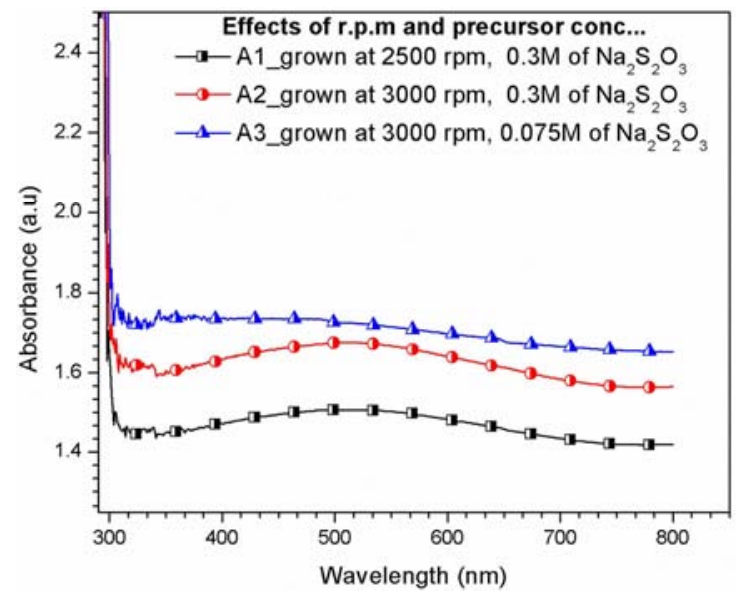

Figure 6. UV-Vis Absorbance Spectra of the films.

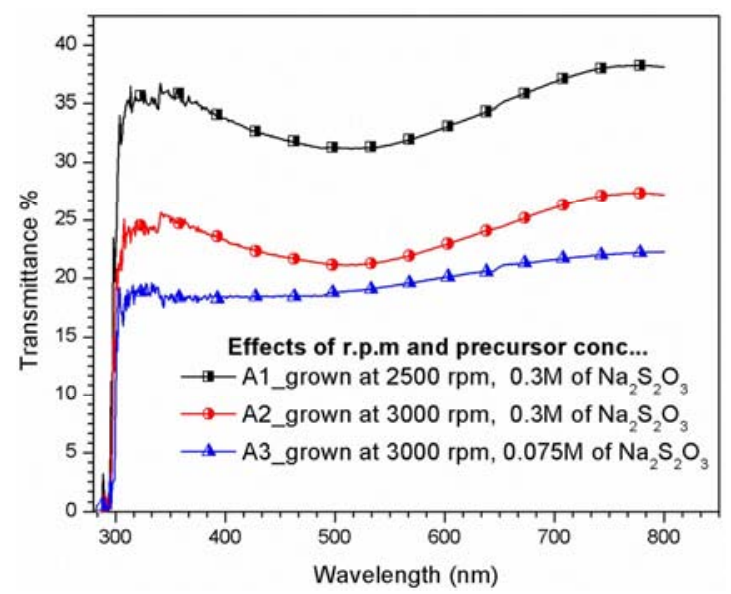

Figure 7. UV-Vis Transmittance Spectra of the Samples.
Figure 7 shows the optical transmittance of the samples. It can be generally seen that all the deposited films exhibit higher absorption and lower transmission throughout the wavelength region. It can be deduced from the spectra that the highest transmittance is about $40 \%$ in sample A1. This implies that all the films possess high absorption [9, 13].

\subsubsection{Absorption Coefficient and Energy Band Gap}

The absorption coefficient, $\propto$, was generated from measured optical data using the relation below

$$
\propto=2.303 \frac{A}{t}
$$

where $t$ is the film thickness and $A$ is the absorbance.

Figures 8 showed the plots of absorption coefficient $(\alpha)$ versus wavelength. It is observed that the absorption coefficients are sufficiently larger than $10^{4} \mathrm{~cm}^{-1}$ in the wavelength region. This suggests that film can effectively absorb photon energy from the visible down to infrared region [13]. Therefore, this material can be considered as a good absorber material for thin film solar cell devices.

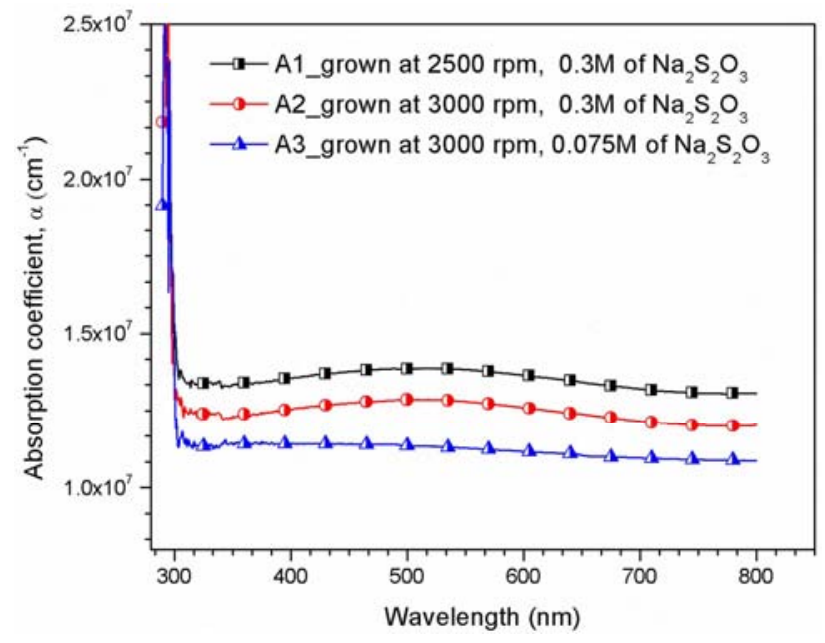

Figure 8. Plot of Absorption coefficient against Wavelength

Tauc's plot for estimating band gap energy was obtained using the equation below:

$$
\alpha h v=A\left(h v-E_{g}\right)^{n}
$$

Where $n=\frac{1}{2}$ for direct allowed transition, $A$ is an empirical constant, $h v$ is the photon energy and $E_{g}$ is the band gap energy. Values of $(\alpha h v)^{2}$ are plotted against $h v$. The band gap energy was estimated by extrapolating the linear portion of the plot to the photon energy axis at $(\alpha h v)^{2}=0$. The plots are shown in Figure 9. It was revealed that the films (A1, A2 and A3) possess direct allowed energy transition with band gap values of $1.30,1.42$ and $1.60 \mathrm{eV}$ respectively. It was also observed from the plots that the band gap energy increases with increase in spin speed. These results are consistent with some reported values for effective photoabsorption in optoelectronic components [13-16]. 


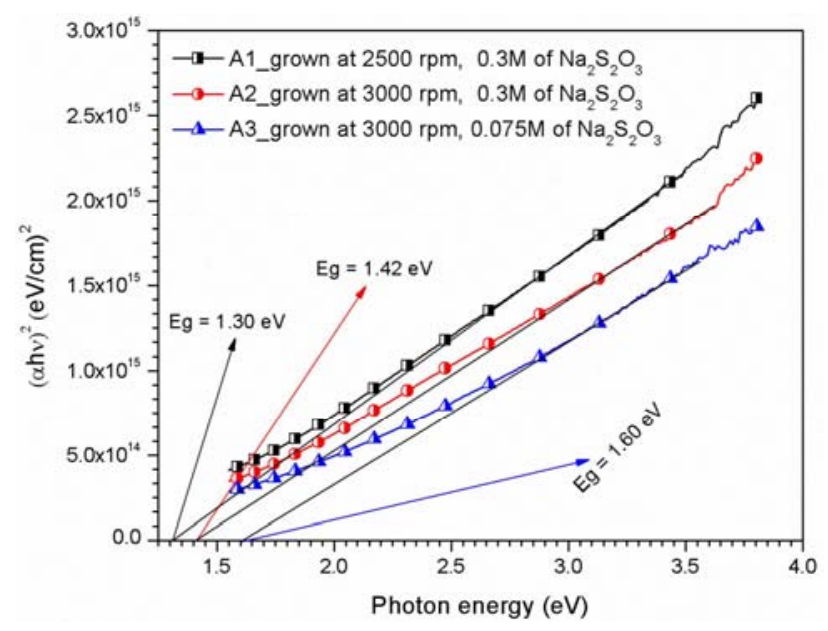

Figure 9. Tauc's plot for estimation of energy band gap.

\subsubsection{Skin Depth}

Conductivity in semiconductors depends strongly on the optical band gap. Therefore, correlation between the optical properties and the skin depth of any semiconductor is desired [17]. The skin (penetration) depth, $\delta$, is related to the absorption coefficient by the following equation:

$$
\delta=\frac{1}{\propto}
$$

Figure 10 showed the dependancy of the skin depth on incident photon energy. It is seen from all the samples that the skin-depth decreases as the incident photon energy increases (wavelength decreases) [18]. For $\lambda$ greater than $\lambda_{\text {cut }}$ off where $\mathrm{h} v=4.17 \mathrm{eV}$, the absorption effect vanishes and reduction in amplitude occurs at longer wavelength [17].

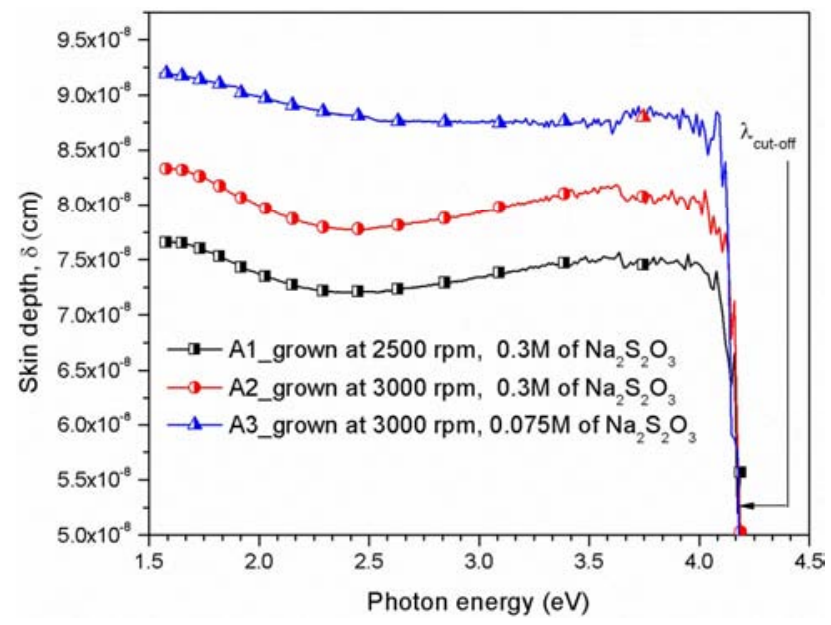

Figure 10. Dependence of skin depth upon the photon energy.

\section{Conclusion}

In this study, spin coating has been successfully used to grow CZT (S, O) on microscopic glass substrates at room temperature. The films were annealed to improve crystallinity and morphology. The presence of multiple characteristic peaks in the XRD patterns showed that the deposited film is polycrystalline. The reflections from all the prominent planes are peculiarities of $\mathrm{Cu}_{2} \mathrm{ZnSnS}_{4}$ tetragonal kesterite structure. The calculated lattice constants are in good agreement with many reports on CZTS thin film. The micrographs revealed that the films are well adhered to the substrate and continuous. The observed nanopores on the film's surface may enhance its performance for solar cell and gas sensing devices. EDX spectra showed peaks corresponding to elements in the film and the substrate. Optical absorption coefficients of the deposited films were observed to be sufficiently larger than $10^{4} \mathrm{~cm}^{-1}$. Estimated direct energy gap suggested that the films can function as a good absorber electrode in optoelectronic devices. The obtained constituent elements from the RBS result revealed that the deposited film is oxy-sulphide with approximated ratio $2: 1: 1: 4: 3$.

\section{Acknowledgements}

This work is supported by TETFUND with Grant Number TETFUND/DESS/UNI/ILE-IFE/2016/RP/VOL. 1. The authors appreciate the support of Mr. M. A. Rahman of Chemistry laboratory, in the Department of Chemistry, Obafemi Awolowo University. Efforts of Mr. B. I. Akinbayo and Mr. A. A. Folorunso in the Department of Physics \& Engineering Physics are also acknowledged. We are also thankful to members of staff of Carbon-Technology laboratory at Department of Physics, University of Pretoria, Pretoria, South Africa for their assistance on SEM and XRD studies.

\section{References}

[1] Murray, C., Norris, D. J., and Bawendi, M. G. (1993). Synthesis and characterization of nearly monodisperseCdE $(\mathrm{E}=$ sulfur, selenium, tellurium) semiconductor nanocrystallites. Journal of the American Chemical Society, 115 (19), 8706-8715.

[2] Tang, J., Hinds, S., Kelley, S. O., and Sargent, E. H. (2008). Synthesis of Colloidal $\mathrm{CuGaSe}_{2}, \mathrm{CuInSe}_{2}$, and $\mathrm{Cu}(\mathrm{InGa}) \mathrm{Se}_{2}$ Nanoparticles. Chemistry of Materials, 20 (22), 6906-6910.

[3] Jeon, M., Shimizu, T., and Shingubara, S. (2011). $\mathrm{Cu}_{2} \mathrm{ZnSnS}_{4}$ thin films and nanowires prepared by different single-step electrodeposition method in quaternary electrolyte. Materials Letters, 65 (15-16), 2364-2367.

[4] Jimbo, K., Kimura, R., Kamimura, T., Yamada, S., Maw, W. S., Araki, H. and Katagiri, H. (2007). $\mathrm{Cu}_{2} \mathrm{ZnSnS}_{4}$-type thin film solar cells using abundant materials. Thin solid films, 515 (15), 5997-5999.

[5] Liu, F., Zhang, K., Lai, Y., Li, J., Zhang, Z., and Liu, Y. (2010). Growth and characterization of $\mathrm{Cu} 2 \mathrm{ZnSnS} 4$ thin films by dc reactive magnetron sputtering for photovoltaic applications. Electrochemical and Solid-State Letters, 13 (11), 379-381.

[6] Moritake, N., Fukui, Y., Oonuki, M., Tanaka, K., and Uchiki, H. (2009). Preparation of $\mathrm{Cu}_{2} \mathrm{ZnSnS}_{4}$ thin film solar cells under non-vacuum condition. physica status solidi c, 6 (5), 1233-1236.

[7] Shen, X., Zhang, C., Feng, Y., Li, W., Chen, G. and Tang, C. (2019). Performance of $\mathrm{Cu}_{2} \mathrm{ZnSn}(\mathrm{S}, \mathrm{Se})_{4}$ solar cells by adding $\mathrm{H}_{3} \mathrm{BO}_{3}$ in the precursor solution, Materials Today communications, https://doi.org/10.1016/j.mtcomm.2019.100558. 
[8] Kamoun, N., Bouzouita, H., and Rezig, B. (2007). Fabrication and characterization of $\mathrm{Cu}_{2} \mathrm{ZnSnS}_{4}$ thin films deposited by spray pyrolysis technique. Thin Solid Films, 515 (15), 59495952.

[9] Parthibaraj, V., Tamilarasan, K., Pugazhvadivu, K. S. and Rangasami, C. (2015). Growth andCharacterization of $\mathrm{Cu}_{2} \mathrm{ZnSnS}_{4}$ Thin Film by RF-Magnetron Sputtering. International Journal of Innovative Research in Science Engineering and Technology. 4 (2) 670.

[10] Subramaniam, E. P., Rajesh, G., Muthukumarasamy, N., Thambidurai, M., Asokan, V. and Velauthapillai, D. (2014). Solar cells of $\mathrm{Cu}_{2} \mathrm{ZnSnS}_{4}$ thin films prepared by chemical bath deposition method. Indian journal of Pure and Applied Physics, 52, 620-624.

[11] Yooa, D., Kima, I., Kima, S., Hahna, C. H., Leeb, C. and Choc, S. (2007). Effects of Annealing Temperature and Method on Structural and optical Properties of TiO2 Films Prepared by RF Magnetron at Room Temperature. Applied Surface Science, Vol. 253, pp. 3888-3892.

[12] Cullity, B. D. and Stock, S. R. (1956). The directions of diffracted beams. Elements of X-ray diffraction, AddisonWesley Publishing Co., USA, 78-103.

[13] Tanaka, K., Fukui, Y., Moritake, N. and Uchiki, H. (2011). Chemical composition dependence of morphological and optical properties of $\mathrm{Cu}_{2} \mathrm{ZnSnS}_{4}$ thin films deposited by solgel sulfurization and $\mathrm{Cu}_{2} \mathrm{ZnSnS}_{4}$ thin film solar cell efficiency. Solar Energy Materials and Solar Cells, 95 (3), 838-842.

[14] Zdanowicz T., Rodziewicz T. and Waclawek M. Z. (2005) Theoretical analysis of the optimum energy band gap of semiconductors forfabrication of solar cells for applications in higher latitudes locations. Solar Energy Materials and Solar Cells, 87, 757-769.

[15] Chung, C., Rhee, D., Yoo, D., Cho, i M., Heo S. C., Kim, D. and Choi, C. (2013) Properties of kesterite $\mathrm{Cu}_{2} \mathrm{ZnSnS}_{4}$ (CZTS) thin filmsprepared by sol-gel method using two types of solution. J Ceram Process Res 14, 255-259.

[16] Islam, S., Hossain, M. A., Kabir, H., Rahaman, M., Bashar, M. S., Gafur, M. A. and Khatun, N. (2015). Optical, structural and morphological properties of spin coated copper zinc tin sulfide thin films. International Journal of Thin Films Science and Technology, 4 (3), 155.

[17] Chiad, S. S. (2015). Optical Characterization of NiO Doped $\mathrm{Fe}_{2} \mathrm{O}_{3}$ thin Films Prepared by Spray Pyrolysis Method. International Letters of Chemistry, Physics and Astronomy, 6, 50.

[18] Hassanien, A. S. and Akl, A. A. (2015). Influence of composition on optical and dispersion parameters of thermally evaporated non-crystalline $\mathrm{Cd}_{50} \mathrm{~S}_{50-\mathrm{x}} \mathrm{Se}_{\mathrm{x}}$ thin films. Journal of Alloys and Compounds, 648, 280-290. 